\title{
Tratamiento informativo del feminicidio en los medios de comunicación digitales chilenos en marzo de 2016: Una aproximación al horizonte actual desde la perspectiva de género
}

\author{
Informative treatment of feminicide on chilean digital media on march 2016: \\ an approach to the current horizon from gender perspective
}

\section{Cecilia Ananías}

Universidad de la Frontera, Chile.

ananiasceciliåagmail.com

\section{Karen Vergara}

Universidad de Chile, Chile.

karen.vergara.sagmail.com

\section{Resumen}

La siguiente investigación busca determinar los principales errores los medios digitales chilenos a la hora de construir noticias sobre feminicidio, centrándose en el análisis de ocho asesinatos de mujeres ocurridos en marzo del 2016, mes en que se conmemora el Día de la Mujer. Para esto, se analizó el tratamiento informativo de cada medio con una perspectiva de género. Se buscó en manuales de género los errores más comunes en noticias sobre violencia contra la mujer, estos errores fueron transformados en categorías y luego, estas categorías fueron aplicadas a 35 noticias de cuatro importantes medios digitales chilenos: BioBioChile.cl, LaTercera. com, SoyChile.cl y Lun.com.

La investigación arrojó que los medios digitales continúan cometiendo los mismos errores que la prensa escrita, que su principal falencia es no contextualizar la información ni concientizar sobre el tema e incluso, se revela que hay una farandulización del asesinato misógino de mujeres.

\section{Palabras clave}

Violencia contra la mujer, feminicidio, medios de comunicación digitales, enfoque de género, periodismo.

\begin{abstract}
This investigation will determinate the mistakes the chilean digital media makes when they build news about feminicide, focusing our attention on the 8 feminicides that happened in march 2016. The idea is to analyze the informative treatment of this subject, looking for common mistakes in the digital media speech, with the guidance of one of the main manuals of gender approach and journalism used in Hispanoamerica.
\end{abstract}

\section{Keywords}

Violence against women, feminicide, digital mass media, gender perspective, journalism. 


\section{Introducción}

Chile bajó de la posición 66 a la 73 en igualdad de género, según el Informe Global de la Brecha de Género 2015 del Foro Económico Mundial. Entre varios factores que marcaron este descenso, está la baja participación laboral femenina: sólo el 46,4\% de las mujeres en edad de trabajar está económicamente activa. Y la mayoría de quienes no lo están (37\%), es por la dedicación a los quehaceres del hogar (Brega, Durán y Sáez, 2015). A esto se le suma la brecha de género, ya que en promedio las mujeres perciben un $17,2 \%$ menos de ingresos que los hombres. Esta brecha se repite en la población de mayor nivel educativo (13 años o más de instrucción), ya que los hombres de este grupo ganan $25,6 \%$ más que las mujeres (CEPAL, 2016). Esto significa que ni siquiera la inversión en educación y capacitación acerca a las mujeres de manera lineal a los ingresos de hombres.

Estas diferencias se repiten en los roles al interior del hogar: un estudio del Instituto Nacional de Estadística llevado a cabo en el Gran Santiago, reveló que el $77,8 \%$ de las mujeres destinan 3,9 horas diarias para realizar trabajo doméstico en días laborales. En el caso de los hombres, sólo el 40,7\% le dedica 2,9 horas a estas tareas y otro $9,2 \%$ admitió hacerlo sólo 1,6 horas entre lunes y viernes (Instituto Nacional de Estadísticas, 2009).

Otro estudio de Images Chile llevado a cabo en 2011 y publicado en diario La Tercera, entrevistó a 1.600 hombres y mujeres de 18 a 59 años, reveló que el $54 \%$ de los hombres cree que el principal rol de la mujer es cuidar del hogar. Increíblemente, un 50\% de las mujeres piensan igual.

Estas son algunas de las expresiones de la desigualdad de género en Chile, la cual toma su forma más dramática a través de la violencia contra las mujeres: en 2014, 40 mujeres fueron asesinadas por sus convivientes o cónyuges y en 2015, la cifra aumentó a 45. Este año, la situación dista de mejorar: hasta el 15 de mayo de 2016, 18 ya habían sido asesinadas y 8 de estos casos se concentraron sólo en marzo, mes en el que se conmemora el Día de la Mujer.

La violencia contra la mujer se considera un delito grave contra los Derechos Humanos y afecta seriamente a nuestro país ${ }^{1}$. A pesar de que los medios de comunicación informan los casos de violencia como algo aislado e incluso, como algo "insólito", una de cada tres mujeres chilenas ha sufrido violencia por parte de algún familiar, pareja o ex-pareja. Y de esta cifra, el $74 \%$ de ellas la recibió de parte de su pareja o ex-pareja. A esto hay que sumar que un $64 \%$ no denuncia, muchas veces por miedo al agresor (Adimark, 2013).

A diferencia de un asalto, robo o secuestro, estas mujeres son violentadas en distintas esferas de su vida sólo por el hecho de ser mujeres. Sus agresores no buscan dañarlas, sino que someterlas bajo sus reglas y demostrarles lo que ocurre si no siguen sus órdenes dentro de la relación. Es por esto que existe un llamado generalizado a denunciar las situaciones de violencia y buena parte de esta labor cae en los medios de comunicación, los cuales "han sido señalados como una institución con una responsabilidad central en la erradicación de la violencia contra las mujeres y (...) en la realización de sus derechos humanos. Al constituirse como una fuente de educación para la sociedad, al lado de la familia y la escuela, tiene una tarea central en la búsqueda de soluciones" (Vega, 2014: 13).

Pero una investigación llevada a cabo en más de 100 países reveló en 2010 que el $46 \%$ de las noticias, tanto en medios impresos como en la TV, promueven estereotipos de género y sólo el $6 \%$ promueve la igualdad de género (Global Media Monitoring Project, 2010). La prensa chilena no es ajena a esto: la portada de La Cuarta que declaraba que un hombre "hizo anticucho con la polola" o el titular de La Tercera que afirmaban que Juliana Acevedo había muerto "por los celos" de su pareja, son sólo algunos de los casos más polémicos.

El dossier "Mujer, Violencia y Medios de Comunicación" difundido en España resume algunos de los principales errores de la prensa a la hora de informar sobre violencia de género. Cabe destacar que al hablar de "errores" en este trabajo se hace en base a dos definiciones de la Real Academia Española: "concepto equivocado o juicio falso" y "cosa hecha erradamente" (Real Academia Española, 2016a); bajo ninguna condición se refiere a un descuido casual. Los descubrimientos de este dossier fueron: la falta de imágenes del género femenino potentes, la 
escasa o nula reflexión, la pérdida de matices debido a la excesiva síntesis, caer en lugares comunes, el morbo y sensacionalismo en el titular y a lo largo del artículo, justificar al atacante y la falta de fuentes adecuadas, son algunos ejemplos (Instituto Oficial de Radio y Televisión, 2002).

Es por esto que el presente trabajo analiza con perspectiva de género el tratamiento informativo del feminicidio en los principales medios de comunicación digitales chilenos, específicamente, sobre los ocho feminicidios ocurridos en marzo del 2016, mes que coincide con la conmemoración del Día de la Mujer.

Si bien existen múltiples investigaciones sobre el tema en España, Latinoamérica y Chile len nuestro país destacan las tesis de Claudia Lagos y Juan Manuel Cabrera), no encontramos estudios centrados en los medios digitales, a pesar de que un reciente estudio de la agencia Reuters arrojó que la mitad de sus encuestados (52\%) se informaba a través de las redes sociales (Mis, 2016).

\section{Marco referencial}

Es necesario precisar conceptos como "violencia contra la mujer" y "feminicidio" (o femicidio), además del rol que cumplen los medios de comunicación en la erradicación de la violencia contra la mujer, antes del análisis.

\section{1 ¿Qué es violencia contra la mujer?}

La violencia de género es un concepto relativamente nuevo, tanto en Chile como en el resto del mundo, ya que hasta la década del 90 sólo se hablaba de "malos tratos" al interior del hogar. No fue hasta 1993, que en la Conferencia Mundial para los Derechos Humanos se redactó la Declaración de las Naciones Unidas sobre la Eliminación de la Violencia contra la Mujer. Ahí se definió que la expresión "violencia contra las mujeres" se refiere a todo acto de violencia sexista que tiene como resultado posible o real un daño de naturaleza física, sexual o psicológica, incluyendo las amenazas, la coerción o la privación arbitraria de la libertad para las mujeres, ya se produzcan en la vida pública o en la privada. Esta puede traducirse en la violencia física, sexual y psicológica en el entorno familiar, en el entorno social o toda aquella violencia contra la mujer perpetrada o tolerada por el Estado (Comisión de Derechos Humanos, 1993).

Posteriormente, en 1994, la Convención Interamericana para Prevenir, Sancionar y Erradicar la Violencia contra las Mujeres, declaró que la violencia contra las mujeres es “cualquier acción o conducta, basada en su género, que cause muerte, daño o sufrimiento físico, sexual o psicológico a la mujer, tanto en el ámbito público como en el privado" (Comisión Nacional de Los Derechos Humanos, 2013). También precisó que "constituye una violación de los derechos humanos" y que "es una ofensa a la dignidad humana y una manifestación de las relaciones de poder históricamente desiguales entre hombres y mujeres". Cabe destacar que este fenómeno trasciende todos los sectores de la sociedad, sin importar edad, raza, clase, cultura, ingresos, educación o religión (Comisión Nacional de Los Derechos Humanos, 2013). Esta forma de violencia es ejercida cuando los hombres "se sienten amenazados o desafiados (...) típicamente se sienten con el derecho de usar cualquier fuerza que sea necesaria para mantener su poder" (Russell en Solyszko, 2013).

\subsection{La violencia contra la mujer como problema estructural}

Se trata de un tipo de violencia estructural, ya que ocurre dentro de una sociedad patriarcal. Como explica Marcela Lagarde, es “una sólida construcción de relaciones, prácticas e instituciones sociales (incluso del Estadol que generan, preservan y reproducen poderes lacceso, privilegios, jerarquías, monopolios, controll de los hombres sobre las mujeres y, al mismo tiempo, conculcan poderes sociales -sexuales, económicos, políticos, jurídicos y culturales a las mujeres" (Lagarde, 2005: 151-164).

Las mujeres y sus cuerpos se convierten en objeto de un ataque que no busca dañar, sino que someter. Como lo indica Foucault, la construcción social del cuerpo como objeto y blanco de numerosos ataques, forman un cuerpo que se manipula, obedece y educa, es decir responde a los discursos de poder (Foucault en Sossa, 2011). 
La dimensión simbólica de las relaciones de dominación se encuentran inscritas en el cuerpo como habitus, de allí la gran estabilidad de un orden social al haber alcanzado la sumisión inmediata, casi natural, de los dominados. La violencia simbólica, más que la violencia física o cualquier otra forma de coacción mecánica, constituye el mecanismo principal de la reproducción social, el medio más potente del mantenimiento del orden. Bourdieu observa que el núcleo de la violencia simbólica se encuentra en la 'doble naturalización' que es la consecuencia de la 'inscripción de lo social en las cosas y en el cuerpo', (Bourdieu en Germaná, 1999: 181).

\section{3 ¿Qué es el feminicidio?}

A diferencia de la percepción que entregan los medios de comunicación, el feminicidio no es el asesinato de una mujer. El término "feminicide" lo acuñó Diana Russel en 1992 y buscaba designar los asesinatos misóginos practicados contra mujeres, alejándolos de la neutralidad de la palabra homicidio.

La mexicana Marcela Lagarde hizo posteriormente la traducción al español como feminicidio. Se caracteriza porque apunta como culpables de la muerte de mujeres al machismo y a la misoginia. Al ocuparlo "implica referirse a un fenómeno social cuya causa no está aislada de la estructura social y por lo tanto es un término teórico y con sentido político" (Solyszko, 2013).

\begin{abstract}
Llamar feminicidio al asesinato misógino elimina la ambigüedad de los términos asexuados de homicidio y asesinato (...) es el extremo de un continuum de terror anti femenino que incluye una gran cantidad de formas de abuso verbal y físico... siempre que estas formas de terrorismo resulten en la muerte son feminicidio (Russell en Solyszko, 2013).
\end{abstract}

Además, Russel aclara que esta forma de violencia es una forma de mantener el patriarcado e incluso, una forma de controlar a aquellas mujeres que se "desalinean" de sus roles tradicionales. El objetivo principal de este término es "desarticular las definiciones de crímenes y homicidios de mujeres por violencia doméstica, violencia intrafamiliar o crímenes pasionales. Con estos términos se invisibiliza el sexo de la víctima y el victimario y se oculta también el uso intencional de la violencia por parte del hombre" (Monárrez, 2006).
Monárrez habla de tres tipos de feminicidio: el feminicidio íntimo, donde el agresor es conocido de la intimidad de la víctima; del feminicidio por ocupaciones estigmatizadas, como es el caso de bailarinas y prostitutas; y el feminicidio sistémico, donde hay un continuum de violencia, como es el caso de mujeres halladas mutiladas, violadas y abandonadas en lugares apartados. A pesar de estas precisiones en el concepto, en Chile, la ley reduce este delito a determinados casos.

Recién en 2010, entra la figura del feminicidio en el Código Penal Chileno, por medio de la inserción de la ley 20.480. Esta declara que "si la víctima del delito es o ha sido el o la cónyuge o conviviente de su autor, el delito tendrá el nombre de femicidio, teniendo la misma sanción que la del parricida, que va de 15 años y un día a presidio perpetuo calificado" (Servicio Nacional de la Mujer). Es decir, el crimen está vinculado a la Ley de Violencia Intrafamiliar y exige cierto grado de intimidad, como haber vivido bajo el mismo techo, tener hijos en común o estar casados legalmente y no incluye otros crímenes de odio hacia las mujeres.

\subsection{Los medios de comunicación y la erradicación de la violencia}

Los medios de comunicación han sido señalados como responsables de ayudar a erradicar la violencia contra la mujer. Sin embargo, la construcción social que periodistas y editores tienen sobre el cuerpo, sexualidad y poder, puede no ser compatible con esta nueva perspectiva de género a la hora de elaborar noticias relacionadas con violencia. Esto fue manifestado en la Conferencia Mundial de la Mujer de Beijing, donde se determinó que los medios de comunicación, empresas de publicidad y sus profesionales deben examinar "las consecuencias de la reproducción de estereotipos sexistas en los contenidos, incluidos aquellos (...) que promueven la violencia y la discriminación de género, y adopten medidas para eliminar estas imágenes negativas" (Vega, 2014).

Es por esto que se ha recomendado impulsar la participación de las mujeres en estos medios, tanto como propietarias como generadoras de contenido. Y finalmente, que se sensibilicen sobre su importante 
rol de “informar y educar a la población acerca de las causas y los efectos de la violencia contra las mujeres y de estimular el debate público del tema" (Vega, 2014).

Pero a pesar de todas estas convenciones, decálogos y tratos, los medios de comunicación continúan describiendo a las mujeres en papeles estereotipados. Como declara Aimeé Vega en uno de sus artículos, “los medios de comunicación, lejos de impulsar el derecho humano de las mujeres a una vida sin violencia, promueven que se les discrimine (...) y lucran con la posibilidad de reproducir la violencia de género" (Vega, 2014). Como resumen esta autora, indica que generalmente a las mujeres las asocian a roles tradicionales o las representan como objetos sexuales o como grupos de consumo. Poco se visibiliza a las mujeres como agentes sociales en áreas como la educación, ciencia, economía, cultura y política.

En los medios de comunicación chilenos, el concepto de feminicidio irrumpe en las noticias el año 2007, como retrata la investigación de Claudia Lagos. El primero en adoptar el concepto es La Cuarta, el 21 de marzo de ese año ("A femicida le entró todo el cuco y se entregó solito a la justicia"). El Mercurio, La Nación y La Tercera incluirán la palabra en mayo del mismo año, cuando se publicó la condena del caso Neira². Eso sí, como describe Lagos, este término aparece más bien "como un recurso apenas descriptivo -femicidio en tanto homicidio de una mujer-y no en su dimensión política y con connotaciones de desigualdades de género" (Lagos, 2008).

Los errores en la elaboración de noticias sobre violencia contra la mujer en la prensa chilena son frecuentes, según recoge esta investigadora. Diferenciación de las víctimas según su estrato social y formación académica, narraciones sensacionalistas, errores al redactar los nombres de los protagonistas de la noticia, omisión de información, justificar al agresor con patologías psiquiátricas, retratar el feminicidio como un drama o tragedia inevitable, retratar el feminicidio como un "arranque" o como un efecto de la "pasión”, atribuirlo al alcohol o drogas, la reproducción de estereotipos y falta de fuentes especializadas fueron algunos de los problemas que identificó (Lagos, 2008).
Ford y Longo señalan que cuando un caso periodístico es tomado por el discurso narrativo, recibe los atributos propios de la story o novela negra: un sujeto principal; comienzo, nudo y desenlace; un auge, caída o cambio de suerte y una voz narrativa identificable (1999). ¿Pero pueden afectar estas noticias mal construidas a la realidad de las mujeres del país? En marzo del 2016, en Chile ocho mujeres murieron en manos de sus esposos o convivientes y muchos de los crímenes ocurrieron dentro de la misma semana e incluso, dos de estos feminicidios ocurrieron el mismo día: el 8 de marzo, fueron asesinadas Nelly Leighton en Tijeral y Amelia García en Paredones.

La explicación a este fenómeno la podemos encontrar en la tesis doctoral de Isabel Marzabal, quien analizó el "efecto imitación” en 30 casos de feminicidio cometidos en Barcelona entre el 2004 y el 2009, concluyendo que la probabilidad que se cometa un nuevo feminicidio aumenta cuando aparecen noticias de asesinatos de mujeres en los medios de comunicación. "Se trata del llamado efecto imitación: el poder de los medios de comunicación para provocar una epidemia de conductas similares" (Red Chilena contra la Violencia hacia las Mujeres, 2016).

También se puede apelar a la construcción social de la mujer violentada en la noticia. Existen dos estereotipos clave a la hora de revisar una noticia relacionada al feminicidio. Está la mujer buena y la mala o incitadora, como indica Gallagher:

La mujer virginal (virgin) de los medios de comunicación se asocia a la subordinación masculina lla carencia de libertad), al puritanismo (o control sexual del hombrel y el sacrificio. Frente al hombre que se representa con independencia, fortaleza y tenacidad. La mujer vampira t es cruel, inhumana, insensible y sin escrúpulos. Es un poderoso objeto sexual que puede subordinar las buenas cualidades de los hombres (Gallagher en Contreras, 2008: 35).

Esto probaría que una noticia sobre violencia contra la mujer mal elaborada y con vívidos detalles de su agresión o asesinato y sin agregar las condenas ni sanciones a los victimarios, tendría efecto en otros agresores. Es decir, los medios de comunicación tienen una influencia prácticamente directa en la erradicación o el aumento de este problema. 


\subsection{Posibles soluciones para la entrega de información con pers- pectiva de género}

Los medios de comunicación deben asumir un rol más activo, no en la victimización de la ciudadanía, ni en instaurar el temor constante, sino en colaborar con los organismos estatales para trabajar en la prevención de la violencia de género, en vez de cubrir los feminicidios cuando éstos ya han sido ejecutados. Así lo señala la investigadora brasileña Rita Laura Segato "hay una condición indispensable: la mediatización de los derechos. La visibilidad de los derechos construye, persuasivamente, la jurisdicción. El derecho es retórico por naturaleza, pero la retórica depende de los canales de difusión, necesita de publicidad. Es necesario que la propaganda y los medios de comunicación en general trabajen a favor de la evitabilidad, y no en su contra" (Segato, 2003).

Cuando nos referimos a los medios de prensa y el uso del lenguaje dentro de un contexto de violencia de género, se deberían rechazar ciertas expresiones e imaginarios sacados de la novela negra, como por ejemplo, poner de titular: la mató por amor, frases que finalmente instauran nuevamente la noción tradicional y sexista de una cultura compuesta por mujeres y hombres que merecen igual tratamiento informativo.

En España se publicó el dossier de prensa, "Mujer, violencia y medios de comunicación", donde se señalan 16 enunciados que pueden colaborar para evitar caer en sesgos a la hora de difundir información relacionada con violencia doméstica. Entre estos enunciados se destaca que el comunicador debe evitar el efecto narcotizante, tener en cuenta que no es una noticia convencional, por lo que no debe ser producida con la plantilla habitual, sino que con cautela y luego de una rigurosa investigación, identificando claramente la figura del agresor y evitando la criminalización de la víctima. También indica que es importante no caer en el morbo, poner atención los testimonios cercanos al agresor o la víctima, destacar si hubo denuncias o procesos judiciales previos, no usar frases hechas y tener cuidado con los adjetivos que se utilizan (Instituto Oficial de Radio y Televisión Española, 2002). “Las palabras difícilmente resultan inocentes, y datos o comentarios en apariencia inofensivos pueden tergiversar gravemente la información. Este tipo de noticias requiere cuidar al máximo la redacción, aun a pesar de una supuesta pérdida de originalidad o brillantez", (Instituto Oficial de Radio y Televisión Española, 2002).

Es importante estudiar cómo los medios de comunicación digitales construyen noticias sobre violencia contra la mujer con resultado de muerte, porque junto a la escuela y la sociedad, son forjadores de opinión y de nuestra noción de mundo. Esto bien lo explica la Teoría de la Mediación social, la cual estudia la producción, transmisión y utilización de la cultura; algo absolutamente necesario, si se considera que la cultura puede ser utilizada como procedimiento de dominación.

“La participación de los Medios de Comunicación de Masas en la elaboración de una representación de lo que sucede en el mundo se inicia cuando la institución mediadora, u otros agentes sociales, seleccionan determinados aconteceres para hacerlos públicos" (Martín, 1993). Como cuando los medios escogen informar o no hacerlo, sobre un caso de violencia contra la mujer.

La Teoría de la Mediación también explica que en los Medios de Comunicación de Masas existen distintos tipos de mediaciones, entre ellas, la "mediación cognitiva" la cual "está orientada a lograr que aquello que cambia tenga un lugar en la concepción del mundo de las audiencias, aunque para proporcionarle ese lugar sea preciso la transformación de esa concepción del mundo" (Serrano, 1993). En este caso, se trataría de la transformación de una sociedad históricamente machista. Además consideramos que hay una ausencia de investigaciones en el área de la Comunicación Social que posean una metodología que incluya el enfoque de género. Esto, es, como indica la abogada costarricense Alda Facio: plasmar una teoría de cómo debe procederse al emplear los mismos métodos que emplean analistas tradicionales para llegar a conclusiones o soluciones no sexistas ni androcéntricas (Facio, 1999: 99-136).

Esto, por supuesto, parte de un marco teórico que permite teorizar sobre cómo se debe proceder frente a un texto noticioso subido a la web, para analizarlo de acuerdo con un método no sexista. Entre los pasos que plantea, se encuentran: tomar conciencia de la subordinación del sexo femenino, identificar las distintas formas en que se manifiesta el sexismo en el texto periodístico, identificar cuál es la mujer que está en la noticia, identificar cuál es la concepción 
de mujer que sirve de sustento al texto y ampliar la toma de conciencia de lo que es el sexismo y cómo puede estar presente en el texto en mayor o menor medida (Facio, 1999: 99-136). También este estudio se enmarca en la Teoría de la Agenda-Setting, ya que "existe una elevada correlación entre los temas a los que dan importancia los medios de difusión y los que interesan a sus audiencias" (LópezEscobar, Llamas \& McCombs, 1996: 9). A raíz de esto, analizaremos qué tanta cobertura se le dio a cada feminicidio y se reflexionará por qué se le dio más espacio en la agenda a algunas víctimas y no a otras.

La Teoría del Framing también nos proporciona herramientas conceptuales y metodológicas importantes para el análisis, ya que ésta se centra en "los efectos cognitivos de los medios de comunicación, en los conocimientos que aportan las noticias a partir sobre todo de la redundancia, de la repetición y a menudo del énfasis en determinados aspectos de los mensajes comunicativos" (Carbadillo, 2010). Esta teoría tiene la particularidad de ir más allá de lo que plantea la agenda setting, "haciendo hincapié en cómo se abordan los temas que son objeto de atención por parte de los medios de comunicación. Trata sobre todo de analizar las perspectivas o vertientes desde las que se abordan esos problemas o temas y como resultado, qué interpretación o imagen prioritaria se ofrece de los mismos" (Carbadillo, 2010).

\section{Metodología}

Se escogió analizar el mes de marzo del 2016, ya que hubo 8 muertes de mujeres en manos de sus cónyuges, convivientes o parejas en el mismo mes en que se celebra el Día de la Mujer; además, varios de los casos ocurrieron con pocos días de diferencia. Luego, se acotó el área de análisis a cuatro medios de comunicación. Cabe destacar que diario La Cuarta no fue incluido en este estudio, ya que ya ha sido ampliamente estudiado en su forma impresa lcomo en la investigación de Claudia Lagos) y porque no tiene el mismo alcance en la web. Los medios a analizar son:

BioBioChile.cl: $6^{\circ}$ lugar de los sitios webs más visitados según el ranking Alexa (junio del 2016), segundo medio digital más leído de Chile.

Lun.com: $7^{\circ}$ lugar de los sitios webs más visitados según el ranking Alexa (junio del 2016), tercer medio digital más leído de Chile.
LaTercera.com: $41^{\circ}$ lugar de los sitios webs más visitados según el ranking Alexa (junio del 2016), cuarto medio digital más leído de Chile.

SoyChile.cl: $96^{\circ}$ lugar de los sitios webs más visitados según el ranking Alexa (junio del 2016), sexto medio digital más leído de Chile. Uno de los más denunciados por incurrir en errores por el Observatorio de Medios.

Tras revisar en los buscadores de cada medio y a través de Google Search, se acotó el cuerpo de análisis a 35 noticias. Después de analizar manuales como el dossier de prensa, "Mujer, violencia y medios de comunicación" del gobierno español, se generó una tabla propia con los errores más comunes que cometen los medios de comunicación, dividiéndolos en siete categorías. Cabe destacar que tomamos dos definiciones de la Real Academia Española para delimitar a qué llamaremos "error" en este trabajo: "concepto equivocado o juicio falso" y "cosa hecha erradamente" (Real Academia Española, 2016). A esto hay que agregar que cuando un periodista informa sobre violencia contra la mujer de manera errada o con un concepto equivocado, lo hace con toda una "mochila" social a sus espaldas y desde una sociedad que es patriarcal, por ende, es un error tanto individual como social y estructural.

Las siete categorías a analizar son:

Cobertura: Publica / No Publica. La no visibilización del tema es tan grave como bombardear con noticias sobre violencia de género. Si los medios no recogen los casos oficiales para integrarlos a su agenda, el tema tampoco entrará en la agenda de los ciudadanos chilenos.

A.- Uso de conceptos erróneos. Como "crimen pasional", "riña o disputa matrimonial", "bajos instintos", "crímenes por amor u honor" y "por cuestiones de celos". Todos estos términos tienden a justificar o atenuar el delito.

B.- Falta de empatía hacia la víctima. No publicar información sensible de forma correcta, afectando a la víctima y a su familia. Presentarlas como responsables de su propio abuso. Destacarla más por su aspecto físico o su rol de madre/esposa.

C.- Justificación del agresor. No caer en atenuantes como un prontuario limpio o su labor en la comunidad. No justificarlo con patologías ("era celópata") ni adicciones (alcoholismo, drogradicción). 
D.- Morbo y sensacionalismo. Frases que magnifican los detalles del hecho de violencia, dejando de lado lo condenable de la situación y la intimidad de la víctima. Titulares escandalosos, frívolos o discriminatorios. Trivialización de la noticia. Uso de adjetivos innecesarios. Sobreexposición de imágenes de la víctima. El morbo ha sido definido como una "atracción hacia acontecimientos desagradables" o "interés malsano por personas o cosas" (Real Academia Española, 2016b); mientras que el sensacionalismo ha sido definido como la "tendencia a producir sensación, emoción o impresión, con noticias, sucesos, etc." por el mismo diccionario (Real Academia Española, 2016c).

E.- Falta de contextualización de la noticia. La noticia debe aportar una serie de datos útiles que ayuden a las víctimas y muestren lo intolerable de la agresión. El feminicidio no debe ser mostrado como un hecho aislado, ni como una tragedia o drama imposible de prevenir. La nota debe ofrecer herramientas a las víctimas (fonos de ayuda, fundaciones o lineamientos a seguir en caso de sufrir violencia), debe mencionar si hubo denuncias o medidas cautelares previas y debe recordar los castigos a los feminicidas, para disuadir agresiones futuras. También debe contar con especialistas que expliquen el fenómeno desde la Psicología, Sociología, Antropología y otras ramas de las Ciencias Sociales y Humanistas.

F.- Discriminación por etnia, religión, condición social, sexualidad o nacionalidad. Destacar detalles como su país de procedencia, profesión o segmento social por sobre el hecho de violencia. Considerar la violencia contra la mujer en familias de clase media y alta como "raros".

Los feminicidios de marzo del 2016 a analizar en estas 35 noticias son: Karen Wilson (31 años, asesinada el 3 de marzo), Silvana Sepúlveda Durán (41 años, asesinada el 5 de marzo), Magali Carriel Garrido
(63 años, asesinada el 7 de marzo), Nelly Leighton Salazar ( 45 años, asesinada el 8 de marzo), Juliana Andrea Acevedo (21 años, asesinada el 9 de marzo), Nancy Arenas Astudillos $(60$ años, asesinada el 10 de marzo) y Yuri Álvarez Valderrama (28 años, asesinada el 25 de marzo).

\section{Análisis}

Análisis del tratamiento informativo de los feminicidios ocurridos en marzo de 2016. La cifra y datos de los casos fueron entregados por el SERNAM. Tras delimitar los ocho feminicidios oficiales de ese mes, se analizaron las informaciones y principales datos entregados por los medios.

\section{Caso 1: Karen Wilson}

Ocurrido el 03 de marzo, en Antofagasta (Región de Antofagastal. Karen Wilson de 31 años, profesora de biología, madre de una niña de 6 años y un niño de 4, fue estrangulada por su cónyuge, Ricardo Huerta, quién trasladó el cuerpo sin vida de la víctima por distintos sectores de la ciudad. No se registran denuncias. Se trató del quinto feminicidio del 2016.

Análisis del caso 1: BioBioChile publicó una sola noticia sobre el caso y SoyChile, cuatro. La Terceray Las Últimas Noticias no cubrieron este caso, lo que da un total de 5 noticias a analizar. Ambos medios que recogieron el caso tienen una amplia cobertura regional y tienden a caer en los mismos errores a la hora de elaborar la noticia. En el caso de BioBioChile se destacan los problemas de ortografía y redacción, que dan a entender un trabajo descuidado a la hora de analizar los hechos y, por otro lado, el morbo excesivo y la poca empatía hacia la víctima, de la cual no sabemos casi nada. Toda la información que

\section{Tabla 1}

\begin{tabular}{|c|c|c|c|c|c|c|}
\hline MEDIO & CATEGORÍA A & CATEGORÍA B & CATEGORÍA C & CATEGORÍA D & CATEGORÍA E & CATEGORÍA F \\
\hline BBCL & $x$ & $x$ & $x$ & $x$ & $x$ & - \\
\hline LA TERCERA & - & - & - & - & - & - \\
\hline LUN & - & - & - & - & - & - \\
\hline SOY CHILE & $x x x$ & $x x$ & $x x$ & $x x$ & $x x$ & - \\
\hline TOTAL & 4 & 3 & 3 & 3 & 3 & 0 \\
\hline
\end{tabular}


este medio entrega es que "el atacante, un hombre de 37 años, quien fue detenido luego de confesar lo suceso, era pareja de la mujer fallecida" (BioBioChile, 3 de marzo de 2016).

El medio SoyChile cae en faltas éticas relacionadas a la justificación del agresor y la nula información sobre la víctima. Se informa que Karen estaba presentando los papeles del divorcio y que tenía una nueva relación. Según este medio "los trámites unilaterales para conseguir el divorcio y los celos por su nueva relación habría desatado el femicidio que cobró la vida de la ex profesora de biología del colegio Netland School de Antofagasta, Karen Wilson Villagrán de 31 años", (SoyChile, 5 de marzo del 2016, destacado nuestro). En una tercera nota, conocemos que era profesora de biología, que el SERNAM incluirá una querella por el femicidio y que sus familiares realizarán un mural en su honor, para concientizar a la población sobre la violencia de género.

\section{Caso 2: Silvana Sepúlveda Durán}

Ocurrido el 05 de marzo en la comuna de Maipú (Región Metropolitana). Silvana Sepúlveda Durán (41 años) era madre de dos hijos y una hija. Fue asesinada por su conviviente, Francisco Marchant Marchant, quien posteriormente se suicidó. El femicida llamó a su hija, que vivía en otra ciudad y ella fue quien alertó a los vecinos que descubrieron el hecho. Se trató del sexto feminicidio de 2016.

Análisis del caso 2: Este femicidio, nuevamente, fue sólo cubierto por BioBioChile (una noticia) y SoyChile (dos noticias), dando una cobertura total de tres noticias. Ni LUN ni La Tercera lo incluyen en su pauta. Se hace énfasis en el morbo del crimen, entregando detalles violentos del hecho, como que Francisco Marchant golpeó a Silvana con un bate de béisbol frente a uno de los hijos pequeños de la víctima y que le narró todo lo ocurrido a una hija que vivía en otra ciudad. También destacar que en las notas no se da a conocer el nombre del victimario, pese a que se suicidó luego de perpetrar el hecho. De Silvana se desconocen más antecedentes, salvo su rol de madre y lo cruel de su asesinato. "El terrible crimen ocurrió en presencia de un pequeño de tan solo tres años, que es el hijo de la fallecida, y quedó al descubierto luego que el asesino llamara a su hija antes de suicidarse" (SoyChile, 6 de marzo del 2016).

\section{Caso 3: Magali Carriel Garrido}

Ocurrido el 7 de marzo en Talcahuano (Región del Bío Bío). Magali Carriel Garrido (63 años) fue degollada por su esposo, Carlos Delgado Delgado. Existían denuncias anteriores de violencia intrafamiliar. Magali se encontraba postrada hace aproximadamente un año, tras sufrir un accidente vascular. El hombre se infirió un corte en la mandíbula y fue detenido. Se trató del séptimo feminicidio de 2016.

Análisis del caso 3: Esta noticia fue cubierta por BioBioChile (con dos noticias) y SoyChile (cuatro noticias). Ni La Tercera ni LUN cubren este caso, dando un cuerpo total de análisis de seis noticias. En esta muerte el morbo relacionado al asesinato aparece como un elemento más importante que el feminicidio como tal. SoyChile difunde más de 4 fotografías donde aparecen los vecinos desconcertados frente a la noticia, de Magali no sabemos mucho más, salvo que estaba postrada hace más de un año debido a un accidente vascular. De la víctima, BioBioChile sólo dice que "la mujer fue identificada como Magaly Carriel Garrido, de 63 años" (BioBioChile, 7 de marzo del 2016). Mientras que SoyChile llegó a culpabilizar a la misma mujer por su feminicidio:

\section{Tabla 2}

\begin{tabular}{l|c|c|c|c|c|c}
\hline MEDIO & CATEGORÍA A & CATEGORÍA B & CATEGORÍA C & CATEGORÍA D & CATEGORÍA E & CATEGORÍA F \\
\hline BBCL & $\mathrm{X}$ & $\mathrm{X}$ & $\mathrm{X}$ & $\mathrm{X}$ & $\mathrm{X}$ & - \\
\hline LA TERCERA & - & - & - & - & - & - \\
\hline LUN & - & - & - & - & - & - \\
\hline SOY CHILE & - & $\mathrm{X}$ & - & $\mathrm{X}$ & $\mathrm{X}$ & - \\
\hline TOTAL & 1 & 2 & 1 & 2 & 2 & 0 \\
\hline
\end{tabular}




\section{Tabla 3}

\begin{tabular}{l|c|c|c|c|c|c}
\hline MEDIO & CATEGORÍA A & CATEgORÍA B & CATEGORÍA C & CATEGORÍA D & CATEgORÍA E & CATEGORÍA F \\
\hline BBCL & - & $\mathrm{XX}$ & - & - & $\mathrm{XX}$ & - \\
\hline LA TERCERA & - & - & - & - & - \\
\hline LUN & - & - & - & - & - & - \\
\hline SOY CHILE & - & $\mathrm{XX}$ & $\mathrm{XX}$ & $\mathrm{XX}$ & $\mathrm{X}$ & - \\
\hline TOTAL & 0 & 4 & 2 & 2 & 3 & 0
\end{tabular}

Si bien, el marido de la mujer no ha confesado el crimen, se conoció que la víctima había denunciado dos veces a su esposo por maltrato. Sin embargo, estas acusaciones no llegaron a judicializarse debido a que Magaly Carriel no ratificaba sus denuncias puesto que defendía a su agresor (SoyChile, 9 de marzo del 2016, destacado nuestrol.

Ambos medios que cubrieron la noticia -SoyChile y BiobioChile-, toman declaraciones emitidas por las autoridades, sin embargo, no incluyen un reporteo previo. Hay una similitud de las cuñas lo que hace deducir que se trataría de comunicados de prensa.

\section{Caso 4: Nelly Leighton}

Ocurrido el 8 de marzo, en Tijerales (Región de la Araucanía). Nelly Leighton Salazar (45 años) fue asesinada por su pareja, José Arriagada Baeza, quien posteriormente se suicidó, todo esto presenciado por el hijo de ambos, de 9 años. Se trató del octavo feminicidio de 2016.

Análisis del caso 4: El caso fue cubierto por BioBioChile (dos noticias) y SoyChile (una noticia), dando un total de cobertura de tres noticias. Ni La Tercera ni LUN incluyen este caso en su pauta. En los medios que lo cubrieron existen errores al momento de describir la localidad (SoyChile informó que el hecho ocurrió en Manzanares, luego en Malleco, siendo que la localidad se llama Tijerales), lo cual denota escaso reporteo.

La víctima es descrita por BioBioChile sólo como pareja, no se conocen más antecedentes de ella: “Este martes Nelly Leighton Salazar, de 45 años, fue asesinada este martes en Renaico por su pareja, José Arriagada Baeza de 49 años, quien posteriormente se suicidó" (BioBioChile, 9 de marzo del 2016).

SoyChile culpó explícitamente el ataque a los celos e hizo mucho hincapié en lo morbosa y trágica de la escena:

Una discusión, motivada aparentemente por celos, derivó en el crimen que acabó con la vida de Nelly del Carmen Leighton Salazar (46), quien fue agredida por su marido, José Rolando Arriagada, quien le propinó un hachazo en la cabeza. La tragedia ocurrió cerca de las 18:00 en el frontis de la propiedad que compartía el matrimonio en el sector rural de la capital de la provincia de Malleco, y en presencia de dos de los tres hijos que tuvo la pareja. Tras agredir con el hacha a su esposa, el agresor huyó del sitio hacia un sitio cercano a la vivienda del sector para quitarse la vida ahorcándose (SoyChile, 9 de marzo del 2016, destacado nuestrol.

\section{Tabla 4}

\begin{tabular}{|c|c|c|c|c|c|c|}
\hline MEDIO & CATEGORÍA A & CATEGORÍA B & CATEGORÍA C & CATEGORÍA D & CATEGORÍA E & CATEGORÍA F \\
\hline BBCL & - & $x \mathbf{x}$ & - & $x x$ & $x$ & - \\
\hline LA TERCERA & - & - & - & - & - & - \\
\hline LUN & - & - & - & - & - & - \\
\hline SOY CHILE & $x$ & $x$ & - & $\mathbf{x}$ & - & - \\
\hline TOTAL & 1 & 3 & 0 & 3 & 1 & 0 \\
\hline
\end{tabular}


En el seguimiento realizado por ambos medios se cuenta que el SERNAM y SENAME intervendrán debido al shock psicológico del hijo de la pareja. Las noticias denotan un posible comunicado de prensa de ambos medios de comunicación. Si bien el uso de comunicados de prensa es de gran valor a la hora de reportear, se hace necesario también contrastar la información y profundizarla más.

\section{Caso 5: Amelia García}

Ocurrido el 8 de marzo en Paredones (Región de O’Higgins). Amelia García de 47 años, dueña de casa y madre de una hija, fue asesinada por su esposo, Juan Humberto Cornejo González. Su feminicidio ocurrió el mismo día en que interpuso una denuncia por VIF. Se trató del noveno feminicidio del 2016.

Análisis del caso 5: Llama la atención la casi nula cobertura que se le dio al caso. Sólo BioBioChile lo cubrió (una sola noticia). Ni SoyChile ni La Tercera ni LUN la recogieron en su pauta. En el caso de la única noticia emitida, se narra el hecho con pocos datos, cayendo en errores como la falta de empatía y una mala contextualización de la nota.

De la víctima se sabe poco, más allá de que había interpuesto una demanda por violencia el mismo día en que fue asesinada. Este detalle, más que generar conciencia en los lectores, se convierte en una advertencia para las futuras mujeres que quieran denunciar:

Juan Humberto Cornejo González, de 49 años, fue acusado de matar a Amelia del Carmen García Correa, de 47 años y madre de 5 hijos. Según los antecedentes, la mujer ese mismo 8 de marzo en la mañana habría denunciado maltrato psicológico en el retén local de Carabineros. Tras ello, fue a visitar a unas amigas, y a ese lugar habría llegado el imputado durante la tarde. Allí discutieron, y luego el hombre habría tomado un cuchillo de la cocina y con él habría dado muerte a la víctima, (BioBioChile, 12 de marzo del 2016, destacado nuestro).

Se intuye que el resto de los medios no publicaron este caso, porque: (a) La cobertura noticiosa en comunas regionales como Paredones es baja, (b) La figura de una madre y dueña de casa de 47 años no es muy atrayente para una noticia y (c) El caso no contaba con detalles muy gráficos o violentos, como los que sí existían en otros casos de feminicidios, como el de Juliana Acevedo o Magali Carriel.

\section{Caso 6: Juliana Acevedo}

Ocurrido el 9 de marzo, en Santiago (Región Metropolitana). Juliana Acevedo de 21 años, trabajadora, fue asesinada y descuartizada por su conviviente, Edwin Vásquez Ortiz. Sus restos fueron hallados en el río Mapocho. Fue ingresada como el feminicidio número 10 del 2016.

Análisis del caso 6: Fue uno de los feminicidios con mayor cobertura del mes, sumando 11 noticias sólo en cuatro medios de comunicación: dos noticias de BioBioChile, tres de LUN, cuatro de La Tercera y dos de SoyChile.

Uno de los errores que más imperó es la falta de contextualización de la noticia, ya que técnicas como incluir fonos de ayuda, las condenas a agresores y explicaciones de expertos en violencia contra la mujer no están incluidas en los rituales de reporteo de los periodistas. LUN no fue capaz de identificar

\section{Tabla 5}

\begin{tabular}{l|c|c|c|c|c|c}
\hline MEDIO & CATEGORÍA A & CATEGORÍA B & CATEGORÍA C & CATEGORÍA D & CATEGORÍA E & CATEGORÍA F \\
\hline BBCL & - & $X$ & - & - & $X$ & - \\
\hline LA TERCERA & - & - & - & - & - \\
\hline LUN & - & - & - & - & - & - \\
\hline SOY CHILE & - & - & - & - & - & - \\
\hline TOTAL & 0 & 1 & 0 & 0 & 1 & 0 \\
\hline
\end{tabular}


cómo el agresor fue cortando los lazos de su víctima y aislándola, señales que estaban presentes en su relato periodístico, pero que no fueron identificadas por no consultar con expertos:

Luisa María dice no saber si Yuliana se alejó de su grupo de amigas porque la relación con Edwin la absorbió o porque éste no la dejaba frecuentar a otras personas. 'Ella no volvió a hablamos a ninguna de nuestro grupo de amigas. Ya no salíamos juntas, ya que ella se la pasaba con él', agrega Luisa María. 'De la relación que ellos tenían no sabía nada. Hasta que supe que se iba a ir con ella a Chile. Es más, ni nos despedimos. No sé qué pasaba con la amistad. No sé si era él quien no la dejaba juntarse conmigo o qué pasaba. Nunca quise preguntárselo', confiesa (LUN, 11 de marzo del 2016, destacado nuestro).

Johan Acosta, vecino y amigo de Yuliana, aporta más detalles. 'Los conocía a ambos. Edwin era celoso cuando estaba con su ex mujer, con la cual tiene un hijo de unos siete u ocho años. Él era muy impulsivo en ese tiempo, no controlaba la rabia', afirma.

La segunda categoría de error que más se repitió, fue el morbo y sensacionalismo: la mayoría de las noticias recogió excesivos detalles de la pelea de Edwin y Juliana y su posterior descuartizamiento y lanzamiento del cuerpo al río Mapocho. La Tercera dio una descripción tan minuciosa de su muerte, que parecía un manual para asesinar. La noticia titulada como "De los celos al horror" recibió tantas críticas, que fue posteriormente borrada de su web:

Durante la discusión, Vásquez comenzó a estrangular a Juliana, cada vez más fuerte hasta que ésta dejó de moverse. Luego, le pegó tres golpes en la tráquea. El cuerpo sin vida de la joven quedó en el departamento de un ambiente, mientras el sospechoso salió a dar una vuelta. Regresó entrada la tarde y llevó el cadáver hasta la tina del baño, donde la desmembró. Usó torniquetes, como cordones y poleras, para frenar la hemorragia de las extremidades. Con este mismo propósito, también les echó agua caliente con sal. Cerca de las 23.00 de esa noche escondió el torso y la cabeza en una maleta. Tomó esta valija e hizo parar un taxi, que lo llevó hasta el puente Cal y Canto. Ahí lanzó el bulto al río Mapocho. Volvió al departamento, durmió, y a la mañana siguiente puso las extremidades en bolsas de supermercado. Tomó un nuevo taxi hasta el mismo puente y repitió la acción (La Tercera, marzo del 2016, destacado nuestro).

La Tercera categoría más importante fue la falta de empatía con la víctima: algunos medios culparon a Juliana de "violencia mutua" y otros apenas recogían datos de su vida, dejándola a ella invisibilizada en el relato. La Tercera lanzó otra cuestionada nota titulada como "La historia de la bella joven que fue descuartizada por su pareja", la cual nuevamente recibió malas críticas y fue borrada de su web:

Los celos provocaban fuertes peleas y bastante seguidas. Una de ellas fue la que provocó la ira de Edwin Vásquez, que terminó asesinando a su polola al interior del departamento que compartían. De acuerdo a los antecedentes de la investigación, el sábado por la tarde la pareja comenzó una discusión por celos, que fue aumentando en intensidad. La joven le pegó en el pecho, al que Vásquez respondió con una cachetada. Aguirre se defendió con un golpe de puño, cuando el sujeto la tomó por el cuello, ahorcándola (La Tercera, marzo del 2016. destacado nuestro).

BioBioChile también culpó a la discusión y ahondó en detalles gráficos:

\section{Tabla 6}

\begin{tabular}{l|c|c|c|c|c|c}
\hline MEDIO & CATEGORÍA A & CATEGORÍA B & CATEGORÍA C & CATEGORÍA D & CATEGORÍA E & CATEGORÍA F \\
\hline BBCL & - & $\mathrm{XX}$ & $\mathrm{XX}$ & $\mathrm{XX}$ & $\mathrm{XX}$ & - \\
\hline LA TERCERA & $\mathrm{X}$ & $\mathrm{X}$ & $\mathrm{X}$ & $\mathrm{XXX}$ & $\mathrm{XXX}$ & $\mathrm{XX}$ \\
\hline LUN & $\mathrm{XX}$ & $\mathrm{XXX}$ & $\mathrm{XX}$ & $\mathrm{XXX}$ & $\mathrm{XXXX}$ & $\mathrm{X}$ \\
\hline SOY CHILE & - & $\mathrm{XX}$ & $\mathrm{XX}$ & $\mathrm{XX}$ & $\mathrm{XX}$ & $\mathrm{X}$ \\
\hline TOTAL & 3 & 8 & 7 & 10 & 11 & 4
\end{tabular}


Ambos protagonizaron una fuerte discusión en el departamento que ambos compartían en calle Huérfanos de Santiago Centro. Esto provocó que Vásquez ahorcara y asfixiara con una cuerda a su pareja para posteriormente trasladarla al baño del inmueble en donde, con un cuchillo carnicero, la descuartizó para posteriormente lanzarlas al río (BioBioChile, 9 de marzo del 2016, destacado nuestrol

Mientras, su asesino era destacado por sus habilidades con la anatomía humana y por ser muy formal y amable, al punto de que se entregó a la policía:

Vásquez, agobiado por la culpa, confesó del homicidio a su jefe quien lo instó a entregarse a la policía. Además, dijo ser ex policía rural de Colombia y que su forma de actuar se debió a su experiencia en torno a este cargo y al hecho de que sus familiares tenían una funeraria en dicho país (BioBioChile, 9 de marzo del 2016. destacado nuestrol.

También, los medios de comunicación online hicieron un excesivo hincapié en que Juliana era una mujer extranjera, de una familia numerosa y pobre de Colombia, siendo que la violencia contra la mujer es un problema transversal a todos los países, culturas y clases sociales. Otro error que se detectó fue el constante cambio de nombre y de trabajo que sufrió la víctima alrededor de todos los relatos lera llamada por su nombre de usuario de Facebook, "Yuliana") y la excesiva exposición de sus imágenes que circulaban en las redes sociales, incluyendo fotos post morten de los tatuajes en sus extremidades; de hecho, Las Últimas Noticias lanzó una noticia titulada “ ¿Por qué Juliana tenía escrito Juan David en la muñeca?" con las imágenes de sus extremidades cercenadas que la Policía de Investigaciones difundió sólo para identificarla.

Este caso parece haber tenido más cobertura que el de otras mujeres asesinadas, porque (a) contaba con fuertes detalles sobre el asesinato y descuartizamiento de Juliana, (b) Juliana era una mujer joven e incluso calificada de "bella" por los periodistas y (c) Ocurrió en Santiago, por lo que era más fácil para los medios de comunicación -todos con sede en esta ciudad-cubrir la noticia. Esto da a entender que en los medios digitales existe una farandulización del feminicidio, es decir, se le da una amplia cobertura como un hecho de farándula cuando genera muchas visitas; esto se traduce en más ganancias para los sitios webs, por lo que también se puede hablar del lucro de la violencia contra la mujer.

\section{Caso 7: Nancy Arenas Astudillo}

Ocurrido el 10 de marzo, en Rinconada de Los Andes. Nancy Arenas de 60 años fue asesinada por su esposo, Fernando Gómez Muñoz, quien posteriormente se suicidó. Fue ingresada como el feminicidio número 11 del 2016.

Análisis del caso 7: El caso de Nancy Arenas fue sólo cubierto por BioBioChile (una noticia). Este medio lanzó una noticia demasiado corta, mal contextualizada y que nuevamente, apenas aportaba datos sobre la víctima. Toda la información que este medio aporta se resume en un párrafo:

El hecho ocurrió en el sector de Rinconada, donde un hombre le disparó en la cara a su pareja y luego se suicidó. Gutiérrez detalló que ambos tenían más de 60 años y vivían solos en un predio que administraban juntos (BioBioChile, 10 de marzo del 2016).

Se intuye que los medios digitales no recogieron su caso, porque: (a) su asesinato ocurrió en un pueblo pequeño, (b) Nancy era una mujer rural, de la tercera edad y dueña de casa, (c) porque no existieron mayores datos gráficos sobre su muerte y (d) porque el caso de Juliana Acevedo estaba acaparando la atención de los periodistas.

\section{Caso 8: Yuri Álvarez}

Ocurrido el 25 de marzo, en Quillón. Yuri Álvarez $(28$ años), vendedora y madre de un hijo, fue asesinada por su cónyuge, Ángelo Iturra. Existía una denuncia 


\section{Tabla 7}

\begin{tabular}{|c|c|c|c|c|c|c|}
\hline MEDIO & CATEGORÍA A & CATEGORÍA B & CATEGORÍA C & CATEGORÍA D & CATEGORÍA E & CATEGORÍA F \\
\hline BBCL & - & $x$ & - & - & $x$ & - \\
\hline LA TERCERA & - & - & - & - & - & - \\
\hline LUN & - & - & - & - & - & - \\
\hline SOY CHILE & - & - & - & - & - & - \\
\hline TOTAL & 0 & 1 & 0 & 0 & 1 & 0 \\
\hline
\end{tabular}

del año 2014. Fue ingresada como el feminicidio número 12 del año 2016.

Análisis del caso 8: Este caso fue recogido por dos medios que suelen cubrir noticias a regiones: BioBioChile (dos noticias) y SoyChile (tres noticias), dando un total de cinco noticias como cobertura; ni La Tercera ni LUN lo recogieron en su pauta.

Nuevamente, la categoría de error que más imperó fue la falta de contextualización de la noticia, ya que el periodista se contenta con informar sobre feminicidios de manera aislada, sin aportar mayores datos que eduquen a la población o que busquen concientizar sobre el tema. Le sigue la falta de empatía con la víctima - de quien no se conocen mayores datos que su edad o que era casada- y la justificación del agresor.

La mujer, tras encerrarse en el dormitorio de su hijo (quien a esa hora se encontraba en la casa de sus abuelos) fue perseguida hasta allí por el hombre, quien utilizó un martillo para romper la chapa y luego, ya dentro de la pieza, procedió a golpearla en reiteradas ocasiones, causándole la muerte (SoyChile, 29 de marzo del 2016).

Por su parte, el defensor penal público, Antonio Guerra, argumentó que al hombre le favorecen al menos dos atenuantes, por el hecho de haberse entregado en la tenencia de carabineros de Quillón (SoyChile, 29 de marzo del 2016, destacado nuestro).

Sólo una noticia de SoyChile informó que Yuri vendía helados y tenía un hijo. Se incluyeron fuentes institucionales, puntualmente del Servicio Nacional de la Mujer, pero siguen sin incluirse las declaraciones de expertos en violencia de género.

\section{Cobertura total y errores}

Los ocho casos de feminicidios fueron cubiertos en 35 noticias, en estos cuatro medios de comunicación digitales. Primaron errores como la falta de empatía hacia la víctima $(68,5 \%)$, morbo y sensacionalismo $160 \%$ ) y especialmente, la falta de contexto en la

\section{Tabla 8}

\begin{tabular}{|c|c|c|c|c|c|c|c|}
\hline MEDIO & COBERTURA & CATEGORÍA A & CATEGORÍA B & CATEGORÍA C & CATEGORÍA D & CATEGORÍA E & CATEGORÍA F \\
\hline $\mathrm{BBCL}$ & PUBLICA: 2 & - & $x$ & - & - & $x$ & - \\
\hline LA TERCERA & NO PUBLICA & - & - & - & - & - & - \\
\hline LUN & NO PUBLICA & - & - & - & - & - & - \\
\hline SOY CHILE & PUBLICA: 3 & - & - & - & - & - & - \\
\hline TOTAL & 5 NOTICIAS & 0 & 1 & 0 & 0 & 1 & 0 \\
\hline
\end{tabular}


Tabla 9

\begin{tabular}{c|c|c|c|c|c|c|c}
\hline & COBERTURA & CATEGORÍA A & CATEGORÍA B & CATEGORÍA C & CATEGORÍA D & CATEGORÍA E & CATEGORÍA F \\
\hline NDENOTICIAS & 35 & 10 & 24 & 13 & 21 & 27 & 4 \\
$\%$ & $100 \%$ & $28,5 \%$ & $68,5 \%$ & $37,1 \%$ & $60 \%$ & $77,1 \%$ & $11,4 \%$ \\
\hline
\end{tabular}

noticia $(77,1 \%)$, como resume la siguiente tabla.

También existió disparidad en la cobertura individual que cada medio le dio a los feminicidios. Los medios digitales chilenos con mayor visitas diarias y que más cubrieron el problema fueron BioBioChile y SoyChile, como resumen la siguiente tabla.

\section{Conclusiones}

Los medios de comunicación digitales de Chile están cometiendo faltas graves en contra de la violencia sexual hacia a las mujeres, errores similares a sus predecesores, los medios de prensa escrita. Ni siquiera las ventajas tecnológicas de estas plataformas, como la posibilidad de utilizar elementos multimedia o de vincular a otras páginas, han permitido mejorar la calidad de información que se entrega a los lectores sobre casos de feminicidio.

Como indica la tabla 10 , la cobertura del feminicidio fue especialmente baja en el diario más comprado en el país, $\operatorname{LUN}(8,5 \%)$ y el segundo diario más importante del país, La Tercera $(11,4 \%)$, donde sólo recogen casos violentos, ocurridos a mujeres jóvenes y dentro de la Región Metropolitana, como ocurrió con Juliana Acevedo y también con otro caso de violencia que no fue archivado como feminicidio por el Sernam: el asesinato de Alison Calderón de 17 años. BioBioChile y SoyChile mantuvieron una cobertura más constante $(34,2 \%$ y $45,7 \%$, respectivamente), por su mayor presencia, recursos y equipo en regiones. Aun así, los artículos de BioBioChile eran demasiado breves y poco contextualizados, basados en despachos radiales o comunicados institucionales, mientras que algunas noticias de SoyChile tenían un excesivo enfoque en los hijos de las víctimas y no en la mujer asesinada.

Como indica la tabla 9, los medios de comunicación mostraron una marcada falta de empatía hacia la víctima $(68,5 \%$ de las noticias analizadas). Rara vez se entregaban detalles sobre sus vidas, más allá de su relación con el agresor o si tenían hijos. En algu-

\section{Tabla 10}

\begin{tabular}{l|c|c}
\hline MEDIO & COBERTURA & $\%$ \\
\hline BBCL & 12 & $34,2 \%$ \\
\hline LA TERCERA & 3 & $8,5 \%$ \\
\hline LUN & 4 & $11,4 \%$ \\
\hline SOY CHILE & 16 & $45,7 \%$ \\
\hline TOTAL & 35 & $100 \%$ \\
\hline
\end{tabular}


nas noticias sus nombres estaban mal escritos y en el caso de Juliana Acevedo, también fue cambiado constantemente su lugar de trabajo; sólo LUN destacó que había hecho un curso para ser contadora.

Mientras muchas víctimas fueron sobreexpuestas en imágenes, de los agresores rara vez se entregaba su nombre ni mucho menos fotografías, a pesar que algunos habían confesado el crimen. En algunas noticias existió justificación de su actuar $(37,1 \%)$, especialmente frente el caso de Juliana Acevedo, donde su asesinato y descuartizamiento fue adjudicado a violencia mutua, celos, amor o al fragor de la discusión. En el caso de Karen Wilson, se hizo mucho hincapié en que acababa de pedirle el divorcio a su agresor y que tenía una nueva relación.

No se encontraron muchos conceptos errados con la ética en los textos periodísticos (28,5\%), excepto algunos artículos referentes a Juliana Acevedo, donde se hablaba de "supuesto agresor" o de "supuesto parricidio", a pesar de que el autor estaba confeso. En otras notas, es evidente la falta de prolijidad en errores ortográficos o de redacción. También, se dio un excesivo morbo -atracción a acontecimientos desagradables- y sensacionalismo en la entrega de información (60\% de las noticias analizadas), especialmente en el caso de Juliana Acevedo.

El error que más imperó fue la falta de contextualización $(77,1 \%$ de las noticias analizadas). Esto indica que los periodistas no incluyen en sus rutinas el entrevistar a expertos, ahondar en la vida de las víctimas; tampoco proporcionan herramientas de ayuda a otras víctimas ni anuncian las condenas de los feminicidas. Se limitan a basarse en relatos policiales o de familiares o cercanos de las víctimas. Por ende, no existe una explicación a por qué ocurre la violencia contra la mujer ni cuáles son las señales de alerta. No hay una concientización de la población y mucho menos habrá prevención.

Si bien esta investigación a los medios digitales chilenos es exploratoria, sus resultados indican que se hace urgente educar a los periodistas y futuros periodistas para que entreguen informaciones con perspectiva de género, que presenten soluciones y concientización sobre el tema. No basta el lanzamiento de manuales -por ejemplo, este 2016 el Instituto Nacional de Derechos Humanos presentó el Manual de Derechos Humanos para Comunicadores y Comunicadoras-, ya que las rutinas aceleradas de los periodistas, la falta de apoyo -monetario o permisos- para su especialización, la constante rotación de personal y los sistemas de turnos no permiten que la información fluya hasta las salas de prensa y mucho menos en medios regionales -por ejemplo, este manual fue sólo lanzado en una universidad de Santiago-. Por eso, creemos que es necesario acercarse directamente a los medios y generar instancias de diálogo y capacitación permanentes, apoyadas por los directores y editores de estos. Reporteros. Sólo así se generará información consciente y la población dejará de ver estos casos de violencia contra la mujer como un hecho aislado o propio de ciertas clases sociales y comenzará a concebirlos como algo transversal a nuestra sociedad, pero que con la debida denuncia y alerta, puede ser prevenido y detenido.

\section{Notas}

1. Diario La Tercera (13 de diciembre de 2011). La mitad de los chilenos cree que el rol de la mujer es cuidar el hogar. Recuperado desde: http://diario.latercera.com/2011/12/13/01/contenido/tendencias/16-93790-9-la-mitad-de-los-chilenos-creeque-rol-de-la-mujer-es-cuidar-el-hogar.shtml

2. El 19 de diciembre, Alfredo Cabrera Opazo golpeó a su ex pareja, Claudia Neira Oportus hasta casi matarla. Su hija en común de 6 años, Javiera, intentó defenderla. A raíz de esto, Alfredo tomó a la niña, subió en ascensor hasta el séptimo piso y la lanzó por el balcón, matándola instantáneamente. 


\section{Referencias bibliográficas}

Adimark (2013). Encuesta Nacional de Victimización por Violencia Intrafamiliar y Delitos Sexuales. Santiago, Chile: Ministerio del Interior y Seguridad Pública. Recuperado desde: http://estudios.sernam.cl/documentos/?eMjM1MTAxOQ==.

Germaná, C. (1999) “Pierre Bourdieu: La Sociología del Poder y la Violencia Simbólica”. Revista de Sociología 11 (12).

Brega, C., Durán, G \& Sáez, B (2015). Mujeres Trabajando: Una exploración al valor del trabajo y la calidad del empleo en Chile. Santiago de Chile: Estudios Fundación Sol.

Carbadillo, P. (2010). El Proceso de Construcción de la Violencia Contra las Mujeres: Medios de Comunicación y Movimiento Feminista. Una aproximación desde la Teoría del Framing. (Tesis doctoral, Universitat Jaime I, Castellón de la Plana, España). Recuperada desde: http:// www.tdr.cesca.es/bitstream/handle/10803/21779/carbadillo.pdf?sequence $=1$

CEPAL (2016). Persiste la brecha salarial entre hombres y mujeres. Observatorio de Igualdad de Género de América Latina y el Caribe, Notas de Igualdad. Recuperado desde: http://www. cepal.org/sites/default/files/news/files/nota_18_brechas_salarios.pdf.

Comisión Nacional de Derechos Humanos (1993). La eliminación de la violencia contra la mujer. Naciones Unidas: Conferencia Mundial para los Derechos Humanos. Recuperado desde: https://www.oas.org/dil/esp/1993-Declaracion_sobre_la_eliminacion_de_la_violencia_contra_la_mujer.pdf

Comisión Nacio nal de Los Derechos Humanos (2013). Convención Interamericana para Prevenir, Sancionar y Erradicar la Violencia contra la Mujer (Convención de Belem do Para). Ciudad de México, Mexico.

Contreras, F. (2008) Perspectivas feministas en el conocimiento y la actividad mediática. En Los medios de comunicación con mirada de género. España: Instituto Andaluz de la Mujer/ Consejería para la igualdad y bienestar social.

Facio, A. (1999). “Metodología para el análisis de género del fenómeno legal”. En Género y Derecho. Santiago de Chile: Ediciones LOM, pp. 99-136.

Ford, A. y Longo, F. (1999). “La exasperación del caso". En La Marca de la Bestia. Buenos Aires, Argentina: Norma, pp. 245-289.

Global Media Monitoring Project (2010). GMMP 2010 Reports. Recuperado desde: http:// whomakesthenews.org/gmmp/gmmp-reports/gmmp-2010-reports

Instituto Nacional de Estadísticas (2009). Encuesta exploratoria de uso del tiempo en el Gran Santiago: ¿Cómo distribuyen el tiempo hombres y mujeres? Santiago, Chile: INE.

Instituto Oficial de Radio y Televisión (2002). Mujer, violencia y medios de comunicación: Dossier de Prensa. Madrid: EGRAF, S.A/ Instituto Oficial de Radio y Televisión.

Lagarde, M. (2005). “El feminicidio, delito contra la humanidad”. En Feminicidio, Justicia y Derecho. México: Comisión Especial para Conocer y dar Seguimiento a las Investigaciones Relacionadas con los Feminicidios en la República Mexicana, pp. 151- 164.

Lagos, C. (2008). El feminicidio según la prensa chilena: Otra forma de violencia contra las mujeres. (Tesis de maestría, Universidad de Chile, Santiago, Chile).

López-Escobar, E., Llamas, J. P. \& McCombs, M. (1996). “Una dimensión social de los efectos de los medios de difusión: agenda-setting y consenso". Comunicación y Sociedad, 9 (1 y 2), 39-65. En Rodríguez Díaz, R. (2004) Teoría de la Agenda-Setting: aplicación a la enseñanza universitaria. España: Observatorio Europeo de Tendencias Sociales. 
Martín, M. (1993). La mediación de los medios de comunicación. Sociología de la Comunicación de Masas I. Gili, México.

Monárrez, J. (2006). “Las diversas representaciones del feminicidio y los asesinatos de mujeres en Ciudad Juárez, 1993-2005”. En Solyszko, I. (2013). “Femicidio y feminicidio: Avances para nombrar la expresión letal de la violencia de género contra las mujeres". GénEros, Revista de investigación y divulgación sobre los estudios de género, 23-41.

Mis, M. (14 de junio de 2016). "More than half online users get news from Facebook, YouTube and Twitter: study". Reuters.

Real Academia Española. (2016a). Error: Diccionario de la lengua española. Madrid, España. Real Academia Española. (2016b). Morbo: Diccionario de la lengua española. Madrid, España. Real Academia Española. (2016c). Sensacionalismo: Diccionario de la lengua española. Madrid, España.

Red Chilena contra la Violencia hacia las Mujeres. (3 de junio del 2016). “Los medios de comunicación frente a la violencia contra las mujeres". El Desconcierto. Recuperado desde: http://www.eldesconcierto.cl/debates-y-combates/2016/06/03/los-medios-de-comunicacionfrente-a-la-violencia-contra-las-mujeres/

Segato, R. (2003). “Las estructuras elementales de la violencia: contrato y status en la etiología de la violencia". Trabajo presentado en Curso de Verano sobre Violencia de Género, Universidad Complutense de Madrid, sede San Lorenzo del Escorial. Recuperado desde: http://www. escuelamagistratura.gov.ar/images/uploads/estructura_vg-rita_segato.pdf.

Servicio Nacional de la Mujer (2014). Las dramáticas cifras del femicidio en Chile. Santiago, Chile: Sernam.

Servicio Nacional de la Mujer (s/f) Ley 20.480 que establece el Femicidio. Chile: Sernam.

Solyszko, I. (2013). “Femicidio y feminicidio: Avances para nombrar la expresión letal de la violencia de género contra las mujeres". GénEros, Revista de investigación y divulgación sobre los estudios de género, 23-41.

Sossa, A. (2011). “Análisis desde Michel Foucault referentes al cuerpo, la belleza física y el consumo". Polis, 28, 1-19.

Vega-Montiel, A. (2014). "El Tratamiento de la Violencia contra las Mujeres en los Medios de Comunicación". Comunicación y Medios 30, 9-25.

\section{Sobre las autoras}

\section{Cecilia Ananías}

Es periodista de la Universidad de Concepción, estudiante de Magíster en Ciencias de la Comunicación en la Universidad de la Frontera.

\section{Karen Vergara}

Es periodista y Bachiller en Humanidades de la Universidad de Concepción, estudiante del Magíster en Estudios de Género y Cultura, mención Humanidades, de la Universidad de Chile.

\section{Cómo citar:}

Ananías, C. \& Vergara, K. (2016). "Tratamiento informativo del feminicidio en los medios de comunicación digitales chilenos en marzo de 2016: Una aproximación al horizonte actual desde la perspectiva de género”. Comunicación y Medios, 25 (34), 52 - 69. 